\title{
Microneedles As a Delivery System for Gene Therapy
}

\author{
Wei Chen ${ }^{1 \dagger}$, Hui $\mathrm{Li}^{2 \dagger}$, De Shi ${ }^{1}$, Zhenguo Liu ${ }^{1 *}$ and Weien Yuan ${ }^{2 *}$ \\ ${ }^{1}$ Department of Neurology, Xinhua Hospital affiliated to the Medical School of Shanghai Jiao Tong University, Shanghai, \\ China, ${ }^{2}$ School of Pharmacy, Shanghai Jiao Tong University, Shanghai, China
}

\section{OPEN ACCESS}

Edited by:

Claudio Bucolo,

University of Catania, Italy

Reviewed by:

Dimitrios I. Zeugolis,

National University of Ireland, Ireland

Christopher Nelson,

Duke University, USA

*Correspondence:

Zhenguo Liu

zhenguoliu2004@aliyun.com.cn

Weien Yuan

yuanweien@126.com

${ }^{\dagger}$ These authors have contributed equally to this work.

Specialty section:

This article was submitted to Pharmaceutical Medicine and

Outcomes Research,

a section of the journal

Frontiers in Pharmacology

Received: 14 February 2016 Accepted: 10 May 2016

Published: 26 May 2016

Citation:

Chen W, Li H, Shi D, Liu Z and Yuan W (2016) Microneedles As a Delivery System for Gene Therapy. Front. Pharmacol. 7:137. doi: 10.3389/fphar.2016.00137
Gene delivery systems can be divided to two major types: vector-based (either viral vector or non-viral vector) and physical delivery technologies. Many physical carriers, such as electroporation, gene gun, ultrasound start to be proved to have the potential to enable gene therapy. A relatively new physical delivery technology for gene delivery consists of microneedles (MNs), which has been studied in many fields and for many molecule types and indications. Microneedles can penetrate the stratum corneum, which is the main barrier for drug delivery through the skin with ease of administration and without significant pain. Many different kinds of MNs, such as metal MNs, coated MNs, dissolving MNs have turned out to be promising in gene delivery. In this review, we discussed the potential as well as the challenges of utilizing MNs to deliver nucleic acids for gene therapy. We also proposed that a combination of MNs and other gene delivery approaches may lead to a better delivery system for gene therapy.

Keywords: micronnedles, gene, delivery, therapy, approaches

\section{INTRODUCTION}

Gene therapy is a technique to transport genetic materials to a specific cell with the aim to correct or compensate for the genetic defects, thereby achieving the goal to treat diseases (Mulligan, 1993). With the development of molecular biology and biotechnology, we can replace the mutant gene in the diseased cells to treat genetic diseases, such as hemophilia, muscular dystrophy, cystic fibrosis (Mulligan, 1993). We can also treat genetic disorders by delivering genetic materials to targeted cells (Pack et al., 2005). The first gene therapy clinical trial started with the severe combined immunodeficiency (SCID) in 1990 (Blaese et al., 1995). Cavazzana-Calvo firstly reported the successful clinical case of gene therapy in April, 2000 (Cavazzana-Calvo et al., 2000). In July 2012, the European Medicines Agency recommended the approval of Glybera, which is a gene therapy for the treatment of lipoprotein lipase deficiency (LPLD) (Bryant et al., 2013; Watanabe et al., 2015).

There have been many clinical trials of gene therapy approved so far, but the success rate has been low (Kay et al., 2000; Khuri et al., 2000). On the other hand, the discovery of the phenomenon of RNA interference may open a new road for the gene therapy (Fire et al., 1998). Compared with the traditional gene therapy, siRNA can efficiently silence the diseased gene and knock down its function. The sequences of siRNAs can be rationally designed to target specific genes. The effects of siRNA can be quick and significant. All the recent progresses make gene therapy enter a new revolution. Recent therapeutic trials of siRNA have been carried out with macular degeneration, diabetic macular edema, solid tumors, respiratory diseases, syncytial virus, and human immunodeficiency viral infections, etc. (Novobrantseva et al., 2008; Castanotto and Rossi, 2009; Whitehead et al., 2009). However, Andrew Z. Fire, the Nobel Prize recipient for discovering RNA interference, said that the lack of efficient delivery systems of siRNA may be the next obstacle for gene therapy when he was awarded on the podium in 2006 (Fire, 2007). 
The big challenge now is to find a safe and efficient delivery system to help genetic materials or siRNAs target to the specific cell. Microneedles (MNs), as a new transdermal delivery system, has the potential to greatly enhance the cutaneous delivery of low, medium, and high molecular weight therapeutic agents (Coulman et al., 2006). Recently, MNs has also been studied to deliver genetic materials for gene therapy (Niidome and Huang, 2002; McCaffrey et al., 2015). In this review, some accessible MNs-based methods for gene delivery with clinical potential will be reviewed and the future prospects of MNs-based delivery systems will also be discussed.

\section{THE EXISTING PROBLEMS OF GENE DELIVERY}

In general, the gene delivery systems have been developed into the following three major types: viral vectors, non-viral vectors, and physical delivery carriers. The related studies have proved their effectiveness in delivering genetic materials or siRNAs. But many critical issues still remained to be solved.

Viral vectors use the natural ability of virus to transport the genetic materials into infected cells. The construction of viral vectors retains the necessary components of the genetic material and knocks down the pathogenic components (McCaffrey et al., 2016). It has been widely applied in clinical trials of gene therapy for retrovirus, lenti virus, adeno-associated virus, and adenovirus, etc (Mountain, 2000; Cots et al., 2013; Kotterman et al., 2015). However, the gene delivery vectors derived from viruses have the potential to be pathogenic because of their potential tumorigenicity and immunogenicity. Moreover, the potential for vector integration and insertional mutagenesis also limits the use of viral vectors (Lentz et al., 2012). In addition, the costly scale-up production, insufficient capacity for cell targeting and low level of transgene expression remind us to find a more safe and effective vector for therapeutic gene delivery (Weinberg et al., 2013).

Non-viral vectors, another kind of vectors that can protect the nucleic acids from degradation and assist cellular entry, can be further divided into lipid cations, cationic polyplexes and others (Guo et al., 2013; Noori-Zadeh et al., 2014; Yin et al., 2014). Lipid cations, or liposome, incorporate, and compact negatively charged DNA into nanoparticles. They can be up-taken into the cytoplasm by endocytosis or membrane fusion. The delivery efficiency of lipid cations is quite high, but lipid cations may cause undesirable membrane destabilization and cytotoxicity. In addition, the unstable batch production makes it hard to be widely applied (Koirala et al., 2013). Cationic polymers, including polyethyleneimine (PEI), poly-L-lysine (PLL), are polymers with cationic groups with positive charge that can compact nucleic acids, including primary amine, secondary amine, tertiary amine, and quaternary amine, etc. Because of the flexibility of chemical structure, cationic polymers-based polyplexes have many possibilities to deliver nucleic acids and cause less cytotoxicity (Noori-Zadeh et al., 2014). However, limited transfection efficiency and the relatively low ability to bind to nucleic acids impeded its clinical application (Xun et al., 2014). Others, like chitosan, modified cyclodextrins (CDs), PLGA, nanobubbles, cell penetration enhancer peptides (Hsu and Mitragotri, 2011; Cavalli et al., 2013; Favaro et al., 2014; Lai, 2014) can complex nucleic acids and form nanoparticles and transfect a wide range of cell types. However, for these carriers, the issues of efficient loading and the optimal duration of therapeutic effects need to be carefully addressed.

Physical delivery carriers depend on physical methods to deliver nucleic acids into cells, such as electroporation, gene gun, ultrasound, hydrodynamics high pressure injection and microneedles (Somiari et al., 2000; Newman et al., 2001; McCaffrey et al., 2016). The delivery process is simple, but the nucleic acids can be degraded by nucleases easily, so in general the nucleic acids need to be chemically modified to improve its stability and biological activity.

\section{THE ADVANTAGES OF MICRONEEDLES FOR GENE THERAPY}

Four major physical methods have been developed so far for the transdermal delivery of therapeutics including ultrasound methods, intradermal injection, gene gun and microneedles (Figure 1). Microneedles (MNs), as a minimally invasive drug delivery system, can deliver both low-molecular weight and high-molecular weight agents, including the nucleic acids into the systemic circulation by penetrating the stratum corneum (SC), which is the main barrier for intradermal drug delivery. Microneedles are shaped with arrays of needles ranging from 25 to $2000 \mu \mathrm{m}$ in height (Donnelly et al., 2010). The needles have different tip shapes and tip intervals, being attached to a base support. The dimension of microneedles is within the micron range, but greater than the size of their cargos, so it will be easy for macromolecules, even drug-excipient complexes or nanoparticles to get through the micro-channels in the microneedles. The application of microneedles is pain-free and patient-friendly, which greatly improves the patient compliance. Since it is easy to use, microneedles also have the potential for self-administration. In addition, the low production cost makes microneedles a promising drug delivery system with marketing potential as well (Coulman et al., 2006).

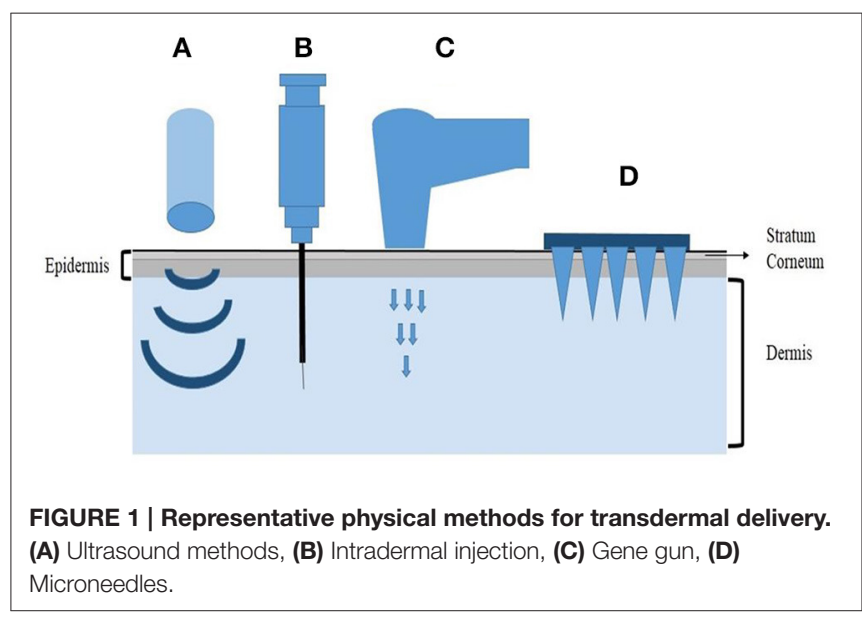


The fabrication of microneedles usually involves many materials, including stainless steel, ceramics, dextrin, polymers and glass (Frazier, 2003; Ito et al., 2006; Ovsianikov et al., 2007; Jiang et al., 2009). Moreover, different fabrication methods have been used to construct microneedles, including chemical isotropic etching method, micro-molding method, the surface/ultrafine processing method, lithographyelectroforming-replication method. Laser-etching prepared microneedles have also been reported Trichur et al., 2002; Moon and Lee, 2005). Based on their properties, microneedles can be divided into several types: solid microneedles, holliow microneedles, dissolving microneedles, and hydrogel microneedles (Liu et al., 2014).

Now microneedles have been used for the transdermal delivery of a broad range of drugs, such as small molecular weight drugs, oligonucleotides, DNA, peptides, proteins, and inactivated viruses. Moreover, extensive experiments with influenza, Calmette-Guérin (BCG), and other vaccines have shown that vaccine delivery into the skin is also promising (Gonzalez-Gonzalez et al., 2009; Haq et al., 2009; Kim Y. C. et al., 2012a; van der Maaden et al., 2012). Recently, microneedles combined with siRNA have been applied as gene therapy. As reported, it can efficiently and reproducibly deliver nucleic acids to the skin for the treatment of genetic skin disorders, cancers, wounds, and hyper proliferative diseases (McLean and Moore, 2011).

\section{THE SOLID MICRONEEDLES}

The solid microneedles are usually made of metals and silicon using dry or wet etching process. By using potassium hydroxide $(\mathrm{KOH})$ solution, the part of silicon needles that are not covered by chromium model can be etched into required shape (Lin and Pisano, 1999). The solid microneedles usually need a two-step application. First, it penetrates the SC to form some transient microchannels. Then the drug solution, or gel, cream, ointment is applied as a form of a patch on the area of skin. Guang Yan et al. (Birchall et al., 2005) developed a motorized metalbased microneedle device for transdermal delivery of plasmid DNA that encoding enhanced green fluorescent protein and firefly luciferase (pEGFP-Luc). The authors found that high gene expression can be obtained and the skin would have minimal damage with the device. In their study, the authors also compared the different methods for the delivery of DNA into the skin, including passive diffusion method, intradermal injection method and motorized microneedle device method for delivering DNA solution. Motorized microneedle device turned out to be more advantageous than the other two methods in equivalent conditions. And the result showed that pretreatment of skin with microneedles followed by application of DNA solution is less effective than the application of DNA solution at first. The gene expression of latter method is 87 times higher than the former one. In addition, Kumar et al. (2012) used Dermaroller ${ }^{\circledR}$ microneedle roller, which is also a kind of solid microneedles made into roller to pretreat the mice skin. Then the plasmid DNA coated on the surface of cationic PLGA nanoparticles are applied onto the microneedle-treated area. The results showed that microneedle-mediated transcutaneous immunization with plasmid DNA carried by the nanoparticles induced a stronger immune response than with the plasmid DNA alone. So the solid microneedles, used as a pretreatment to deliver nucleic acids subcutaneously appears to be promising.

\section{THE COATED SOLID MICRONEEDLES}

The coated solid microneedles avoid a two-step application, which uses a dip-coating method to coat the proteins, DNA, viruses or microparticles onto the surface of the needles. The material used to fabricate the microneedles can be metal, silicon or even polymer materials. Pearton et al. (2012) fabricated the steel microneedles into $75 \mu \mathrm{m}$ thick using an infrared laser. An optimized dip-coating process was used to coat the pDNA onto the MNs, of which the loading capacity is up to $100 \mu \mathrm{g}$ of pDNA per 5-microneedle array. They believed that suitable DNA loading, efficient and reproducible skin puncture and rapid in vivo dissolution of pDNA at the treated site determine the efficiency of gene expression from coated microneedles. Chong et al. (2013) used wire electrical discharge machining (EDM) to fabricate the stainless steel microneedle devices which contained either 5 or 10 needles of $700 \mu \mathrm{m}$ length and $200 \mu \mathrm{m}$ base width. A coating reservoir was used to load BLOCK-iT ${ }^{\mathrm{TM}}$ Alexa 647 fluorescent siRNA into a pipette tip and microneedles. The theoretical loading onto each microneedle device was $35 \mu \mathrm{g}$ siRNA. The fluorescence image showed that the coating of 0.1 $\mu \mathrm{g}$ fluorescent siRNA on the surface of a single steel microneedle was removed from the surface after a 10 min insertion, which verified the distribution of siRNA. For in vivo studies, the microneedles were coated with self-delivery siRNA targeting the reporter genes (luciferase/GFP). The intravital imaging of reporter gene expression and the quantification of reporter mRNA confirmed the functionality of gene silencing following microneedle delivery. The results demonstrated that coated solid MNs have the potential to deliver nucleic acids in vivo. The further study should focus on the delivery of larger doses of therapeutic siRNAs.

\section{THE DISSOLVING MICRONEEDLES}

Dissolving microneedles are always made of biodegradable polymers, which can dissolve or degrade within the skin. As a result, there is no need to remove the MNs from patients' skin. Compared with coated microneedles, dissolving microneedles have bigger loading capacity. The drugs loaded into the needles can quickly release after the insertion into the skin (Donnelly, 2011). Lee et al. (2011) used a hybrid electro-microneedle (HEM) to achieve a safe and high-capacity gene transfer. The monolithic fabrication process of the HEM is shown in Figure 2. The HEM is a monolithic hybrid assembly of a dissolving microneedle and an electrode. The electrode was used as a drawing pillar to elongate dissolving microneedles from 2D glassy maltose. The needles are separated by antidromic isolation in the melting process. The dissolving microneedles have an ultra-sharp tip diameter of $5 \mu \mathrm{m}$ and a length of $400 \mu \mathrm{m}$. The cutaneous permeation and release tests showed that the microneedles of the HEM dissolved completely in $20 \mathrm{~min}$ after insertion into 


\begin{tabular}{|c|c|c|c|}
\hline A & B & C & D \\
\hline $\begin{array}{l}\text { Liquid state } \\
\text { (over } T \mathrm{~m} \text { ) }\end{array}$ & $\begin{array}{l}\text { Glassy state } \\
\left(T_{\mathrm{m}}-T_{\mathrm{g}}\right)\end{array}$ & $\begin{array}{l}\text { Solid state } \\
\text { (under } T \mathrm{~g} \text { ) }\end{array}$ & $\begin{array}{l}\text { Liquid state } \\
\text { (over } T_{m} \text { ) }\end{array}$ \\
\hline $\begin{array}{l}\text { Contact with the } \\
\text { electrode of the HEM } \\
\text { (drawing pillar) }\end{array}$ & $\begin{array}{l}\text { Creation of } \\
\text { elongated structure } \\
\text { by drawing lithography }\end{array}$ & Curing & $\begin{array}{l}\text { Fabrication of the } \\
\text { dissolving microneedle } \\
\text { of the HEM by antidromic } \\
\text { isolation }\end{array}$ \\
\hline \multicolumn{4}{|c|}{$\begin{array}{l}\text { FIGURE } 2 \text { | The monolithic fabrication of a HEM by drawing lithography } \\
\text { with antidromic isolation. (A) Liquid maltose was coated on a planar } \\
\text { surface, and contacted with the } 5 \times 5 \text { array electrodes of the HEMs as a } \\
\text { drawing pillar. (B) The glassy maltose between Tm and Tg was elongated by } \\
\text { drawing of electrodes. (C) After lowering the temperature to sub-Tg, the } \\
\text { elongated 3D structures were cured to a solid state. (D) The coating surface } \\
\text { was melted at a temperature greater than Tm to isolate elongated 3D } \\
\text { structures from 2D coating surface, and this antidromic isolation fabricated } \\
\text { dissolving microneedles of the HEMs. Adapted with permission from (Lee } \\
\text { et al., 2011). }\end{array}$} \\
\hline
\end{tabular}

the skin. Then the electrode applied electric pulse to facilitate intracellular transfection of nucleic acids into cells at the release site. Compared with the negative controls (pCMV-GLuc with dissolving microneedles alone and the control PCI plasmid with HEM), the bioluminescence intensity achieved by pCMV-GLuc transfer with the HEM was significantly higher after 8 to 15 days. The regression of subcutaneous B16F10 by cutaneous p2CMVmIL-12 transfer using a HEM also lead to a longer survival time of 45 days for the tested mice.

Gonzalez-Gonzalez et al. (2010) applied a PAD (Protrusion Array Device) loaded with a fluorescently tagged siRNA mimic (siGLO Red) onto the mice footpad. They fabricated the dissolving microneedles under a controlled airflow. A pin template contacting with a thin film of PVA solution was withdrawn to form a fiber-like structure, which then was trimmed to a uniform height with sharp tips. The distribution and silencing of CBL/hMGFP reporter gene demonstrated that endogenously expressing genes can be reduced $25-50 \%$ by Accell siRNAs delivered by PADs. And they proposed a combinatorial approach of PAD and Accell may result in greater efficiency to knock down the target gene.

Lara et al. (2012) also used the PAD to load CD44 sdsiRNA both in vitro and in vivo. The treatment with CD44 sd-siRNA decreased CD44 mRNA levels, resulting in a reduction of the target protein as confirmed by immunodetection. The results demonstrated that administration of dissolvable microneedle arrays, loaded with sd-siRNA can reduce expression of a targeted endogenous gene in a human skin xenograft model. Based on these favorable results, the dissolving microneedles could be a good alternative to deliver genetic materials. A graphic illustration of the mechanisms of different microneedles for therapeutics delivery is shown in Figure 3.

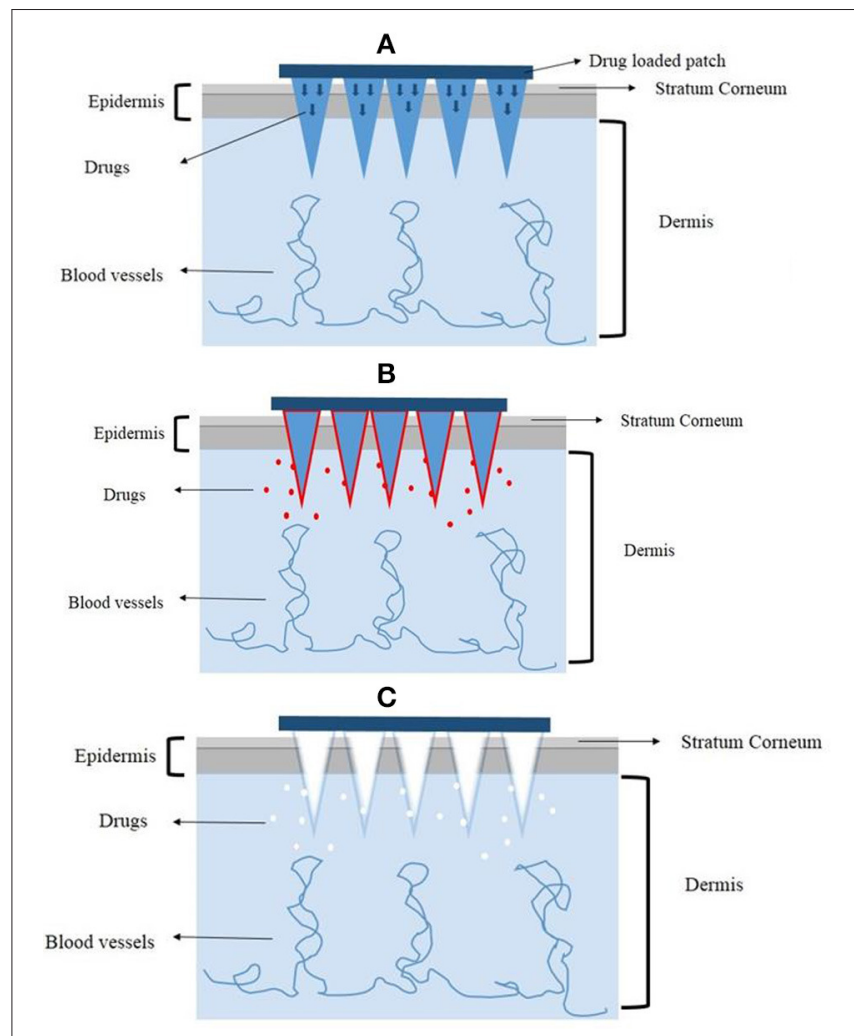

FIGURE 3 | The mechanisms of different microneedles to deliver drugs. (A) The solid microneedles. (B) The coated microneedles. (C) The dissolving microneedles.

\section{THE EXISTING PROBLEMS OF MNS TO BE USED FOR GENE THERAPY}

Although the microneedles have been verified as an effective and potentially useful way to deliver siRNA or other nucleic acids into the skin, many problems still remained to be addressed.

The motorized solid microneedle device utilized by Birchall et al. (2005) may have the concerns of costly fabrication and the two-step application still increases the inconvenience of self-administration. In addition, the treated skin needed to be punctured for sufficient long duration to get the high gene expression in the skin. During the application, the motorized microneedle device could cause some undesirable damage to the skin, though the study claims to only cause the minimal damage. Moreover, the breakdown of microneedles in the skin may be another potential safety problem for solid microneedles.

The coating of coated microneedles could be restricted to the tips of microneedles. Devices used to enhance the depth of skin penetration may also be a potential issue (Coulman et al., 2011). The coating formulations and procedures may limit the penetration of skin and efficient drug deposition at the targeted site, since the viscosity and surface tension of the formulation could affect the uniform coating of the microneedles (Chong et al., 2013). In addition, the coating capacity could be another problem. Pearton et al. (2012) reported 
the fabrication of the coated microneedles with high doseloading of pDNA (up to $100 \mu \mathrm{g}$ of pDNA per 5-microneedle array). However, compared with other kinds of microneedles, the loading capacity of the coated microneedles still needs to be improved.

The dissolving microneedles is composed of biodegradable polymers, which has the potential issue of biocompatibility in vivo. Since the dissolving microneedles almost dissolve completely after the insertion into the skin, we should pay attention to the safety and biocompatibility of these dissolving materials and their degradation products. Moreover, the release kinetics of the dissolving microneedles depends on the internal structure of the polymer material, which could be an obstacle for the delivery into the skin. In addition, some microneedle fabrication procedures involve high polymermelting temperatures, some are even above $135^{\circ} \mathrm{C}$, which will be damaging to some temperature-sensitive drugs, such as proteins and nucleic acids. Another issue is that the loading amount of drugs may also affect the needle mechanical properties when the main matrix is PLGA or carboxymethyl cellulose. For example, Kim M. et al. (2012b) found that microneedles with $10 \%$ drug loading could not keep the mechanical strength to penetrate the skin. In addition, for therapeutic nucleic acids, the intracellular barriers including endosome escape, releasing from carriers, and entering into nucleus could be additional challenges. Combining MNs and nanoparticle-based formulations could be a potentially useful approach to overcome these intracellular barriers (Kumar et al., 2012; McCaffrey et al., 2016).

Because of the properties of MNs, the application site is limited to some certain area on the body, such as arms, hands, abdomen where the epidermis and SC are easier for MNs to penetrate. As reported, the dissolving microneedles dissolved completely in $20 \mathrm{~min}$ (Lee et al., 2011), so the duration time for the application is also critical.

No matter solid microneedles, coated microneedles, dissolving microneedles, or hollow microneedles, the MNs are used as a physical delivery method. For gene therapy, the

\section{REFERENCES}

Birchall, J., Coulman, S., Pearton, M., Allender, C., Brain, K., Anstey, A., et al. (2005). Cutaneous DNA delivery and gene expression in ex vivo human skin explants via wet-etch micro-fabricated micro-needles. J. Drug Target. 13, 415-421. doi: 10.1080/10611860500383705

Blaese, R. M., Culver, K. W., Miller, A. D., Carter, C. S., Fleisher, T., Clerici, M., et al. (1995). T lymphocyte-directed gene therapy for ADA- SCID: initial trial results after 4 years. Science 270, 475-480. doi: 10.1126/science.270.5235.475

Bryant, L. M., Christopher, D. M., Giles, A. R., Hinderer, C., Rodriguez, J. L., Smith, J. B., et al. (2013). Lessons learned from the clinical development and market authorization of Glybera. Hum. Gene Ther. Clin. Dev. 24, 55-64. doi: 10.1089/ humc.2013.087

Castanotto, D., and Rossi, J. J. (2009). The promises and pitfalls of RNA-interference-based therapeutics. Nature 457, 426-433. doi: 10.1038 /nature 07758

Cavalli, R., Bisazza, A., and Lembo, D. (2013). Micro- and nanobubbles: a versatile non-viral platform for gene delivery. Int. J. Pharm. 456, 437-445. doi: 10.1016/j.ijpharm.2013.08.041 cargo nucleic acids also need to be improved. MNs facilitating the delivery of genetic material alone may not be better than intradermal injection, but the combination of MNs and electroporation proved to be more effective than injection alone, which gives us a thought of the combined use of different delivery techniques. While the other physical delivery carriers have some shortages such as damages to the skin, the costly fabrication and patient-unfriendly etc., MNs behaves well at those aspects, and the electrically controlled pulse may further improve its efficiency. And some bioactive components can also be added into the formulation of dissolving microneedles to enhance its effects. Moreover, the advantage of pain-free application makes microneedles to act as an optimal strategy for DNA vaccination. MNs could relieve the patients from the suffering of multiple injections from days to weeks to develop immunization.

In conclusion, the further development of microneedles for gene therapy depends not only on the improved fabrication of MNs, such as the structures, the mechanical properties and the formulations etc., but also on the combined use of different delivery techniques to achieve optimal therapeutic outcomes.

\section{AUTHOR CONTRIBUTIONS}

WY and ZL conceived and participated in its design, searched databases, extracted and assessed studies and helped to draft the manuscript. WC, HL, and DS participated in the conceptualization and design of the experiment, data extraction and analysis, WC, and HL wrote the manuscript. All authors read and approved the final manuscript.

\section{ACKNOWLEDGMENTS}

The study was supported by the Projects of National Science Foundation of China (No. 81200871) and Funds for Interdisciplinary Projects of Medicine and Engineering by Shanghai Jiao Tong University (No.YG2013MS52, YG2015MS06, YG2014QN06 and YG2013MS62).
Cavazzana-Calvo, M., Hacein-Bey, S., de Saint Basile, G., Gross, F., Yvon, E., Nusbaum, P., et al. (2000). Gene therapy of human severe combined immunodeficiency (SCID)-X1 disease. Science 288, 669-672. doi: 10.1126/science.288.5466.669

Chong, R. H. E., Gonzalez-Gonzalez, E., Lara, M. F., Speaker, T. J., Contag, C. H., Kaspar, R. L., et al. (2013). Gene silencing following siRNA delivery to skin via coated steel microneedles: in vitro and in vivo proof-of-concept. J. Control. Release 166, 211-219. doi: 10.1016/j.jconrel.2012.12.030

Cots, D., Bosch, A., and Chillón, M. (2013). Helper dependent adenovirus vectors: progress and future prospects. Curr. Gene Ther. 13, 370-381. doi: 10.2174/156652321305131212125338

Coulman, S., Allender, C., and Birchall, J. (2006). Microneedles and other physical methods for overcoming the stratum corneum barrier for cutaneous gene therapy. Crit. Rev. Ther. Drug Carrier Syst. 23, 205-258. doi: 10.1615/CritRevTherDrugCarrierSyst.v23.i3.20

Coulman, S. A., Birchall, J. C., Alex, A., Pearton, M., Hofer, B., O’Mahony, C., et al. (2011). In vivo, in situ imaging of microneedle insertion into the skin of human volunteers using optical coherence tomography. Pharm. Res. 28, 66-81. doi: 10.1007/s11095-010-0167-x 
Donnelly, R. F. (2011). "Microneedle-mediated intradermal delivery," in Microneedle-mediated Transdermal and Intradermal Drug Delivery, eds R. F. Donnelly, T. R. R. Singh, D. I. J. Morrow, and A. D. Woolfson (Chichester: Blackwell), 16.

Donnelly, R. F., Raj Singh, T. R., and Woolfson, A. D. (2010). Microneedle-based drug delivery systems: microfabrication, drug delivery, and safety. Drug Deliv. 17, 187-207. doi: 10.3109/10717541003667798

Favaro, M. T. P., de Toledo, M. A. S., Alves, R. F., Santos, C. A., Beloti, L. L., Janissen, R., et al. (2014). Development of a non-viral gene delivery vector based on the dynein light chain Rp3 and the TAT peptide. J. Biotechnol. 173, 10-18. doi: 10.1016/j.jbiotec.2014.01.001

Fire, A., Xu, S., Montgomery, M. K., Kostas, S. A., Driver, S. E., and Mello, C. C. (1998). Potent and specific genetic interference by double-stranded RNA in Caenorhabditis elegans. Nature 391, 806-811. doi: 10.1038/35888

Fire, A. Z. (2007). Gene silencing by double-stranded RNA (Nobel Lecture). Angew Chem Int. Ed. Engl. 46, 6966-6984. doi: 10.1002/anie.200701979

Frazier, S. C. B. (2003). Characterization of surface micromachined metallic microneedles. Microelectromech. Syst. 12, 289-295. doi: 10.1109/JMEMS.2003.811731

Gonzalez-Gonzalez, E., Ra, H., Hickerson, R. P., Wang, Q., Piyawattanametha, W., Mandella, M. J., et al. (2009). siRNA silencing of keratinocyte-specific GFP expression in a transgenic mouse skin model. Gene Ther. 16, 963-972. doi: $10.1038 /$ gt.2009.62

Gonzalez-Gonzalez, E., Speaker, T. J., Hickerson, R. P., Spitler, R., Flores, M. A., Leake, D., et al. (2010). Silencing of reporter gene expression in skin using siRNAs and expression of plasmid DNA delivered by a soluble protrusion array device (PAD). Mol. Ther. 18, 1667-1674. doi: 10.1038/mt.2010.126

Guo, J., Evans, J. C., and O'Driscoll, C. M. (2013). Delivering RNAi therapeutics with non-viral technology: a promising strategy for prostate cancer? Trends Mol. Med. 19, 250-261. doi: 10.1016/j.molmed.2013.02.002

Haq, M. I., Smith, E., John, D. N., Kalavala, M., Edwards, C., Anstey, A., et al. (2009). Clinical administration of microneedles: skin puncture, pain and sensation. Biomed. Microdevices 11, 35-47. doi: 10.1007/s10544-008-9208-1

Hsu, T., and Mitragotri, S. (2011). Delivery of siRNA and other macromolecules into skin and cells using a peptide enhancer. Proc. Natl. Acad. Sci. U.S.A. 108, 15816-15821. doi: 10.1073/pnas.1016152108

Ito, Y., Hagiwara, E., Saeki, A., Sugioka, N., and Takada, K. (2006). Feasibility of microneedles for percutaneous absorption of insulin. Eur. J. Pharm. Sci. 29, 82-88. doi: 10.1016/j.ejps.2006.05.011

Jiang, J., Moore, J. S., Edelhauser, H. F., and Prausnitz, M. R. (2009). Intrascleral drug delivery to the eye using hollow microneedles. Pharm. Res. 26, 395-403. doi: 10.1007/s11095-008-9756-3

Kay, M. A., Manno, C. S., Ragni, M. V., Larson, P. J., Couto, L. B., McClelland, A., et al. (2000). Evidence for gene transfer and expression of factor IX in haemophilia B patients treated with an AAV vector. Nat. Genet. 24, 257-261. doi: $10.1038 / 73464$

Khuri, F. R., Nemunaitis, J., Ganly, I., Arseneau, J., Tannock, I. F., Romel, L., et al. (2000). A controlled trial of intratumoral ONYX-015, a selectively-replicating adenovirus, in combination with cisplatin and 5-fluorouracil in patients with recurrent head and neck cancer. Nat. Med. 6, 879-885. doi: 10.1038/78638

Kim, M., Jung, B., and Park, J. H. (2012b). Hydrogel swelling as a trigger to release biodegradable polymer microneedles in skin. Biomaterials 33, 668-678. doi: 10.1016/j.biomaterials.2011.09.074

Kim, Y. C., Park, J. H., and Prausnitz, M. R. (2012a). Microneedles for drug and vaccine delivery. Adv. Drug Deliv. Rev. 64, 1547-1568. doi: 10.1016/j.addr.2012.04.005

Koirala, A., Conley, S. M., and Naash, M. I. (2013). A review of therapeutic prospects of non-viral gene therapy in the retinal pigment epithelium. Biomaterials 34, 7158-7167. doi: 10.1016/j.biomaterials.2013.06.002

Kotterman, M. A., Chalberg, T. W., and Schaffer, D. V. (2015). Viral vectors for gene therapy: translational and clinical outlook. Annu. Rev. Biomed. Eng. 17, 63-89. doi: 10.1146/annurev-bioeng-071813-104938

Kumar, A., Wonganan, P., Sandoval, M. A., Li, X., Zhu, S., and Cui, Z. (2012). Microneedle-mediated transcutaneous immunization with plasmid DNA coated on cationic PLGA nanoparticles. J. Control. Release 163, 230-239. doi: 10.1016/j.jconrel.2012.08.011

Lai, W. F. (2014). Cyclodextrins in non-viral gene delivery. Biomaterials 35, 401-411. doi: 10.1016/j.biomaterials.2013.09.061
Lara, M. F., González-González, E., Speaker, T. J., Hickerson, R. P., Leake, D. Milstone, L. M., et al. (2012). Inhibition of CD44 gene expression in human skin models, using self-delivery short interfering RNA administered by dissolvable microneedle arrays. Hum. Gene Ther. 23, 816-823. doi: 10.1089/hum.2011.211

Lee, K., Kim, J. D., Lee, C. Y., Her, S., and Jung, H. (2011). A high-capacity, hybrid electro-microneedle for in-situ cutaneous gene transfer. Biomaterials 32, 7705-7710. doi: 10.1016/j.biomaterials.2011.06.058

Lentz, T. B., Gray, S. J., and Samulski, R. J. (2012). Viral vectors for gene delivery to the central nervous system. Neurobiol. Dis. 48, 179-188. doi: 10.1016/j.nbd.2011.09.014

Lin, L. W., and Pisano, A. P. (1999). Silicon-processed microneedles. J. Microelectromech. Syst. 8, 78-84. doi: 10.1109/84.749406

Liu, S., Jin, M.-N., Quan, Y.-S., Kamiyama, F., Kusamori, K., Katsumi, H., et al. (2014). Transdermal delivery of relatively high molecular weight drugs using novel self-dissolving microneedle arrays fabricated from hyaluronic acid and their characteristics and safety after application to the skin. Eur. J. Pharm. Biopharm. 86, 267-276. doi: 10.1016/j.ejpb.2013.10.001

McCaffrey, J., Donnelly, R. F., and McCarthy, H. O. (2015). Microneedles: an innovative platform for gene delivery. Drug Deliv. Trans. Res. 5, 424-437. doi: 10.1007/s13346-015-0243-1

McCaffrey, J., McCrudden, C. M., Ali, A. A., Massey, A. S., McBride, J. W., McCrudden, M. T., et al. (2016). Transcending epithelial and intracellular biological barriers; a prototype DNA delivery device. J. Control. Release 226, 238-247. doi: 10.1016/j.jconrel.2016.02.023

McLean, W. H. I., and Moore, C. B. T. (2011). Keratin disorders: from gene to therapy. Hum. Mol. Genet. 20, R189-R197. doi: 10.1093/hmg/dldr379

Moon, S. J., and Lee, S. S. (2005). A novel fabrication method of a microneedle array using inclined deep x-ray exposure. J. Micromech. Microeng. 15, 903-911. doi: 10.1088/0960-1317/15/5/002

Mountain, A. (2000). Gene therapy: the first decade. Trends Biotechnol. 18, 119-128. doi: 10.1016/S0167-7799(99)01416-X

Mulligan, R. C. (1993). The basic science of gene therapy. Science 260, 926-932. doi: $10.1126 /$ science. 8493530

Newman, C. M., Lawrie, A., Brisken, A. F., and Cumberland, D. C. (2001). Ultrasound gene therapy: on the road from concept to reality. Echocardiography 18, 339-347. doi: 10.1046/j.1540-8175.2001.00339.x

Niidome, T., and Huang, L. (2002). Gene therapy progress and prospects: nonviral vectors. Gene Ther. 9, 1647-1652. doi: 10.1038/sj.gt.3301923

Noori-Zadeh, A., Mesbah-Namin, S. A., Tiraihi, T., Rajabibazl, M., and Taheri, T. (2014). Non-viral human proGDNF gene delivery to rat bone marrow stromal cells under ex vivo conditions. J. Neurol. Sci. 339, 81-86. doi: 10.1016/j.jns.2014. 01.025

Novobrantseva, T. I., Akinc, A., Borodovsky, A., and de Fougerolles, A. (2008). Delivering silence: advancements in developing siRNA therapeutics. Curr. Opin. Drug Discov. Dev. 11, 217-224.

Ovsianikov, A., Chichkov, B., Mente, P., Monteiro-Riviere, N. A., Doraiswamy, A., and Narayan, R. J. (2007). Two photon polymerization of polymer-ceramic hybrid materials for transdermal drug delivery. Int. J. Appl. Ceram. Technol. 4, 22-29. doi: 10.1111/j.1744-7402.2007.02115.x

Pack, D. W., Hoffman, A. S., Pun, S., and Stayton, P. S. (2005). Design and development of polymers for gene delivery. Nat. Rev. Drug Discov. 4, 581-593. doi: $10.1038 /$ nrd1775

Pearton, M., Saller, V., Coulman, S. A., Gateley, C., Anstey, A. V., Zarnitsyn, V., et al. (2012). Microneedle delivery of plasmid DNA to living human skin: Formulation coating, skin insertion and gene expression. J. Control. Release 160, 561-569. doi: 10.1016/j.jconrel.2012.04.005

Somiari, S., Glasspool-Malone, J., Drabick, J. J., Gilbert, R. A., Heller, R., Jaroszeski, M. J., et al. (2000). Theory and in vivo application of electroporative gene delivery. Mol. Ther. 2, 178-187. doi: 10.1006/mthe. 2000.0124

Trichur, R., Kim, S., Zhu, X., Suk, J. W., Hong, C.-C., Choi, J.-W., et al. (2002). "Development of plastic microneedles for transdermal interfacing using injection molding techniques," in Micro Total Analysis Systems, Vol. 1, eds Y. Baba, S. Shoji, and A. van den Berg (Dordrecht: Springer Netherlands), 395-397.

van der Maaden, K., Jiskoot, W., and Bouwstra, J. (2012). Microneedle technologies for (trans)dermal drug and vaccine delivery. J. Control. Release 161, 645-655. doi: $10.1016 /$ j.jconrel.2012.01.042 
Watanabe, N., Yano, K., Tsuyuki, K., Okano, T., and Yamato, M. (2015). Re-examination of regulatory opinions in Europe: possible contribution for the approval of the first gene therapy product Glybera. Mol. Ther. Methods Clin. Dev. 2:14066. doi: 10.1038/mtm. 2014.66

Weinberg, M., Samulski, R. J., and McCown, T. J. (2013). Adeno-associated virus (AAV) gene therapy for neurological disease. Neuropharmacology 69, 82-88. doi: 10.1016/j.neuropharm.2012.03.004

Whitehead, K. A., Langer, R., and Anderson, D. G. (2009). Knocking down barriers: advances in siRNA delivery. Nat. Rev. Drug Discov. 8, 129-138. doi: $10.1038 / \mathrm{nrd} 2742$

Xun, M.-M., Liu, Y.-H., Guo, Q., Zhang, J., Zhang, Q.-F., Wu, W.-X., et al. (2014). Low molecular weight PEI-appended polyesters as non-viral gene delivery vectors. Eur. J. Med. Chem. 78, 118-125. doi: 10.1016/j.ejmech.2014.03.050
Yin, H., Kanasty, R. L., Eltoukhy, A. A., Vegas, A. J., Dorkin, J. R., and Anderson, D. G. (2014). Non-viral vectors for gene-based therapy. Nat. Rev. Genet. 15, 541-555. doi: 10.1038/nrg3763

Conflict of Interest Statement: The authors declare that the research was conducted in the absence of any commercial or financial relationships that could be construed as a potential conflict of interest.

Copyright (c) 2016 Chen, Li, Shi, Liu and Yuan. This is an open-access article distributed under the terms of the Creative Commons Attribution License (CC BY). The use, distribution or reproduction in other forums is permitted, provided the original author(s) or licensor are credited and that the original publication in this journal is cited, in accordance with accepted academic practice. No use, distribution or reproduction is permitted which does not comply with these terms. 